\title{
DO REI AO VIZINHO DO NONO ANDAR
}

\section{FROM THE KING TO THE NINETH FLOOR 'S NEIGHBOR}

\section{Tiago Dantas Germano* PUCRS}

Resumo: Este artigo faz um apanhado da crônica como gênero literário, enfatizando sua ocorrência no Brasil, da Carta ao Rei D. Manuel (1500), assinada por Pero Vaz de Caminha (1450-1500) - apontada como primeira manifestação do gênero em território brasileiro -, até as crônicas Carta ao Prefeito (1952) e Recado ao Senhor 903 (1953), assinadas por Rubem Braga (1913-1990) - principal autor do gênero no país. Partindo de um resgate etimológico da palavra, o texto faz um retrospecto da crônica nas culturas oriental e ocidental até o seu aporte no Brasil, ainda no formato que a consagrou de início, como relato de viagem cuja interlocução se dava com figuras de poder como o então representante da monarquia portuguesa. Ao fim, analisa-se a substituição dessas figuras de poder pelos leitores diários do jornal, onde a crônica adquiriu sua popularidade e sua forma moderna, mais próxima da que hoje conhecemos.

Palavras-chave: Literatura. Jornalismo. Crônica. Hibridismo. Gêneros Literários.

\author{
* Doutorando em \\ Escrita Criativa pelo \\ Programa de Pós- \\ Graduação em Letras \\ da Pontifícia Uni- \\ versidade Católica \\ do Rio Grade do Sul. \\ E-mail: tiago.germa- \\ no@acad.pucrs.br
}

\begin{abstract}
This paper makes an overview of the chronicle as a literary genre, giving enphasis to its ocurrence in Brazil, from the Letter to the King of Portugal (1500), signed by Pero Vaz de Caminha (1450-1500) - the first genre's document in Brazilian territory - to the chronicles Letter to the Mayor (1952) and Message to Sr. 903 (1953), both signed by Rubem Braga (1913-1990) - one of the most famous authors of chronicles in Brazil. Starting from an etymological explanation of the genre, it makes a retrospective of the chronicle in the Western and Eastern culture until its arrival in Brasil, still in its original form, as a travel report to the portuguese crown. In the end, it analyses the substitution of those power figures as kings by the newspapers' daily readers, who gave to the chronicle its popularity and its modern form, closer to what we know today.
\end{abstract}

Keywords: Literature. Journalism. Chronicle. Hybrids. Literary genres.

\section{Introdução}

A ligação da crônica com o tempo é ancestral e já está presente na etimologia da palavra. Do grego khrónos (“tempo”, em tradução literal), que originou chronikós ("relativo ao tempo"), a palavra latina chronica designa um gênero narrativo responsável pelo registro "dos acontecimentos históricos, verídicos, numa sequência cronológica, sem um aprofundamento ou interpretação dos fatos” (ALMEIDA, 2008, p. 1, grifos meus). 
Segundo Massaud Moisés (s.d., p. 101), esta relação da crônica com o “cronológico” e o "verídico” que, em uma palavra, podemos resumir no conceito de "realidade”, permanece indissociável no início da era cristã, quando ela "designava (...) uma lista ou relação de acontecimentos ordenados segundo a marcha do tempo, isto é, em sequência cronológica”.

Na Bíblia, chama-se de Crônicas o conjunto de dois livros históricos do antigo testamento que possui 65 capítulos e foi posteriormente desmembrado em dois: o primeiro livro, com 29 capítulos, faz uma longa genealogia do povo de Israel (de Adão aos descendentes de Saul) e narra o reinado de Davi até o seu falecimento (970 a. C.); o segundo, com 36 capítulos, narra o período que vai do reinado de seu sucessor Salomão até a destruição do reino de Judá (586 a. C.) por Nabucodonossor, imperador da Babilônia.

A tradição judaica e cristã divergem quanto a autoria de ambos os livros. De acordo com a Bíblia de Jerusalém (2002, p. 34), sua possível assinatura é a de um levita de Jerusalém que a escreveu numa época posterior a Esdras e Neemias, posto não haver qualquer menção a estes; já a Bíblia cristã (1994, p. 1439-1440) atribui seu advento ao mesmo autor dos livros de Esdras e Neemias, cuja redação se deu entre 350 a.C. e 200 a.C., com alguns acréscimos feitos possivelmente no ano de 200 a.C.

Como se vê, a tradição da crônica não é de exclusividade da cultura ocidental. No Egito Antigo (3150 a.C. - 30 a.C), os faraós utilizavam antes o mesmo expediente que os reis cristianos utilizavam em suas campanhas guerreiras. Encontrados durante a passagem de Napoleão pelo Egito, os manuscritos em papiro denominados Crônica Demótica, hoje armazenados na Biblioteca Nacional da França, constituem um texto profético que dá conta de três séculos da dinastia egípcia, vaticinando a aparição de um herói nativo que ascenderia ao trono e restauraria a ordem e a justiça sobre o Egito. ${ }^{1}$

No Japão, o primeiro livro oficial de história intitula-se Nihon Shoki (“Crônica do Japão”) e é uma obra em dois volumes editada pelo príncipe Toneri no Miko (676-735) a fim de abarcar todo o período que vai da era mitológica aos domínios da imperatriz Jitō (645-703). Segundo Seto (2000, p. 01), este livro complementa um registro mais remoto: uma antiga compilação de histórias japonesas chamada Kojiki ("Crônica de Assuntos Antigos”), que tinha como objetivo a descrição dos primeiros registros da Terra do Sol Nascente numa linguagem mitológica, remetendo à origem das coisas de acordo com a visão xintoísta.

Obviamente, à distância de pelo menos um milênio, tais documentos historicamente relacionados aos primórdios da crônica têm muito pouco a ver com o gênero tal como conhecemos hoje no Brasil, após a revolução cultural proporcionada pelo nascimento da imprensa e seu flerte com outros gêneros literários na França, como o folhetim e o ensaio.

Mais breve e suscetível a uma verdade que se desloca do fato histórico em sua raiz coletiva para o fato banal em suas ramificações pessoais, a
${ }^{1}$ Ver Bresciani, 1994, p. 276-277. 
crônica contemporânea perdeu um tanto de sua validade documental e passou a caracterizar-se melhor como uma apreciação bastante subjetiva de uma realidade que, não poucas vezes, se aproxima muito mais da realidade fictícia.

Permanece, porém, o apego a uma cronologia linear, que na contemporaneidade se condensa numa só unidade: o recorte de tempo feito pelo cronista, que não é mais o escriba de um rei ou de um faraó - ele é o seu próprio escriba, e outorga a si mesmo o poder de mover os ponteis do relógio ou virar a ampulheta, fazendo escorrer por ela uma areia que tanto pode ser a do seu próprio passado, presente e futuro, como o do passado, presente e futuro das pessoas que o cercam.

Se o tempo, sobretudo o presente, segue como um elemento nuclear da crônica contemporânea, cabe nos perguntarmos se outros elementos que hoje lhe dão forma não são igualmente notáveis em suas origens, no longo e tortuoso percurso que a crônica traçou em seu firmamento como gênero narrativo. O que um texto como a Carta ao Rei D. Manuel, de Pero Vaz de Caminha, teria a nos dizer, por exemplo, sobre uma crônica escrita quatro séculos depois por Rubem Braga? Ou sobre uma crônica publicada hoje num jornal ou, indo mais além, num blogue?

Há, naquela missiva, algo equivalente, algum prenúncio do que viria a ser a crônica brasileira - esse gênero que, não sendo exclusivamente nacional (como logo mais veremos), tornou-se quase que um produto tipicamente brasileiro?

Eis a questão que nos move e o objetivo principal deste artigo.

\section{A Carta ao Rei e a condição híbrida da crônica}

Não houve quem melhor se apropriasse dos equívocos que pairam em torno da Carta ao Rei D. Manuel que o pesquisador Jorge de Sá, autor de uma plaquete fundamental sobre a história da crônica no Brasil.

Aproveitando-se da reputação (discutível em vários aspectos) de que a missiva de Pero Vaz de Caminha seria algo como uma pedra angular da literatura brasileira, Sá (2005, p. 06) postula: “A história da nossa literatura se inicia, pois, com a circunstância de um descobrimento: oficialmente, a literatura nasceu da crônica.”

Trata-se, claro, de um lapso de grandiosidade a que se permite um dos porta-vozes de um gênero que, ao ser definido, ganha a pecha costumeira de "gênero menor", como não é raro se referirem a ele alguns escritores que o praticam e como se referiu a ele o próprio Antonio Candido (2003, p. 89), num texto não menos basilar para o estudo da crônica: o breve ensaio A vida ao rés do chão.

Pedra angular ou não de nossa literatura, o relato de viagem de Pero Vaz de Caminha é, quiçá, o mais importante registro desta incursão de Portugal no território de sua futura colônia. A crônica de um viajante, 
fidalgo português designado pela coroa como escrivão da armada de Pedro Álvares Cabral; um testemunho que, dada a sua relevância documental (em que pese a visão etnocêntrica de um europeu do século 16), dificilmente é estudada pela sua matriz cronística, pela herança que deixou para um gênero que, posteriormente, como o colonizador português, iria adaptar-se à atmosfera do Novo Continente e aqui fixar raízes, gerando uma cultura híbrida, diversa da europeia.

Como a colônia que se deu a conhecer através de uma carta para depois, três séculos mais tarde, tornar-se independente por vias de um decreto, a crônica, que se deu a conhecer no país pelas 27 folhas manuscritas de Caminha, migraria mais ou menos na mesma época para as páginas dos jornais, tão logo a novidade da imprensa chegasse a um Brasil em vias de se tornar uma nação.

Pensando por essa perspectiva, a carta de Pero Vaz de Caminha é talvez uma boa metáfora para retratar a condição híbrida da crônica: um gênero estrangeiro que, até a sua chegada ao jornal (seu mais consagrado suporte), foi antes narrativa oral e epistolar, tal qual os cenários descritos pelo escrivão que, até se tornarem ambiente para uma literatura genuína (produzida e lida por brasileiros), tiveram que antes servir à pena e à leitura de burocratas portugueses.

Se a literatura no Brasil não nasce da crônica, sua formação pelo menos se dá em paralelo às metamorfoses desse gênero que, diferente do romance e do conto, se mostrou muito mais influenciável diante das transformações tecnológicas e muito mais camaleônico perante as transições midiáticas por elas impostas.

Nos apetecendo continuar recorrendo à carta de Caminha como metáfora conceitual, pode-se dizer que, neste percurso que ela trilha entre mídias (carta, jornal, internet, livro), a crônica faz um escambo que acaba por se tornar sua verdadeira essência, a razão de sua permanência como gênero enquanto muitos desses meios vão caindo em desuso, numa franca obsolescência.

Sua inserção no jornal, por exemplo, se deu através do folhetim, este gênero que tanto serviu, também, ao romance. Do folhetim, esta invenção do francês Émile de Girardin que tornou seu pequeno jornal La Presse o primeiro fenômeno de cultura midiática do mundo ${ }^{2}$, a crônica herdou sua frequência no jornal e muito provavelmente o seu trânsito, a porosidade que

${ }^{2}$ Ver Reis, 2011, p. 11.

ela ainda conserva nos dias das páginas efêmeras dos tabloides para as mais duráveis do livro encadernado.

Mas estamos nos adiantando. Porque ainda não respondemos à pergunta anterior: o que terá herdado a crônica contemporânea da crônica de viagem? No caso mais específico da Carta ao Rei D. Manuel, o que terá oferecido ela de escambo, quando se deu este primeiro salto da crônica de uma correspondência oficial a um veículo impresso que se propunha servir, ao mesmo tempo, de fonte de informação e entretenimento para a burguesia brasileira nascente, em meados do século 19 ? 
Para tanto, tentaremos traçar um estudo comparativo entre a crônica de Pero Vaz de Caminha e duas crônicas da autoria de Rubem Braga: Carta ao Prefeito e Recado ao Senhor 903.

\section{Do rei ao prefeito}

Toda literatura é um lugar de interlocução.

Em sua brilhante tese de doutoramento, o escritor Amilcar Bettega Barbosa (2012, p. 21) faz referência ao belo elogio à literatura que Marcel Proust faz ao prefaciar a própria tradução em francês do Sésame et les Lys, do poeta e crítico de arte britânico John Ruskin. No texto, Proust se permite a discordar de Ruskin que, capitulando uma ideia já presente em Descartes, defende que "a leitura de bons livros seria como uma espécie de conversa que mantemos com as pessoas de grande espírito, os maiores do passado, que são precisamente os autores destes livros” (BARBOSA, 2012, p. 21)

Para Proust, bem como para Bettega Barbosa, a literatura, pelo contrário, não pode ser comparada exatamente a uma conversa pois, ao passo que nos comunicamos como outro pensamento, permanecemos a sós conosco, “continuamos a gozar do poder intelectual que temos na solidão e que a conversa dissipa imediatamente, continuamos a poder ser inspirados, continuamos em pleno trabalho fecundo do espírito sobre ele próprio" (PROUST, 1973, p. 29 apud BARBOSA, 2012, p. 21).

Apesar de o contraponto de Proust e Bettega Barbosa a Ruskin ser muito pertinente no que concerne à literatura clássica, e sua formação fundada na estética do romance e do mito do “escritor encastelado”, ela parece insustentável diante da contemporaneidade, em que a literatura está cada vez mais impingida deste diálogo (“diálogo”, aqui, no sentido menos filosófico e mais pragmático mesmo: do leitor numa relação física e direta com o autor, que enfim se corporifica, acompanhando sua obra em lançamentos e eventos literários), e diante de gêneros como a crônica, que teve o seu DNA epistolar constantemente estimulado por espaços de diálogo com o leitor, como as colunas dos jornais ou, mais recentemente, as redes sociais.

O tom epistolar da Carta ao Rei já se revela em suas primeiras linhas, nas quais Pero Vaz de Caminha evoca a figura do Rei Dom Manuel I e alude a outras correspondências oficiais remetidas a Sua Alteza pelo Capitão-Mor de sua frota e por outros capitães que também davam notícias à realeza do achamento das novas terras. À maneira dos poetas épicos, Caminha vale-se do recurso da invocação épica a fim de dar início ao seu relato:

Senhor:

Posto que o Capitão-mor desta vossa frota, e assim os outros capitães escrevam a Vossa Alteza a nova do achamento desta vossa terra nova, que ora nesta navegação se achou, não deixarei também de dar disso minha conta a 
Vossa Alteza, assim como eu melhor puder, ainda que -- para o bem contar e falar -- o saiba pior que todos fazer.

Tome Vossa Alteza, porém, minha ignorância por boa vontade, e creia bem por certo que, para aformosear nem afear, não porei aqui mais do que aquilo que vi e me pareceu. (CAMINHA, 2015, p. 05).

Segundo Christina Ramalho (2013, p. 374), a invocação épica “constitui, tradicionalmente, um recurso de efeito retórico relacionado a uma pretensa disparidade entre a dimensão do texto que vai ser escrito e o fôlego do poeta para realizá-lo”. Usando desse expediente, Caminha posta-se humildemente diante do rei, como um súdito que, diante do trono, curva-se numa reverência ensaiada. Adiante, Caminha segue em sua "invocação”, justificando que, em sua carta, não dará conta "da marinhagem e singraduras” (“porque não o saberei fazer, e os pilotos devem ter esse cuidado”), e ao começar a narrar a partida de Belém, traz a figura de Dom Manuel para tão perto de si que já se permite reportar a ele utilizando os verbos "falar" e "dizer" ("Portando, Senhor, do que hei de falar começo e digo”).

Na crônica Carta ao Prefeito, de Rubem Braga, a informalidade não é alcançada a tão duras penas, embora em seu primeiro parágrafo o cronista também se reporte a uma autoridade evidenciando uma certa condição de inferioridade - inferioridade esta que, aqui, não está destacada a pretexto de uma reverência à posição superior do interlocutor, mas de elevar a própria inferioridade do cronista à categoria de salvaguarda para suas impertinências e para o dever de seu interlocutor (o prefeito) de ouvi-lo. Vejamos:

Senhor Prefeito do Distrito Federal:

Eu sou um desses estranhos animais que têm por habitat o Rio de Janeiro; ouvi-me, pois, com o devido respeito. Sou um monstro de resistência e um técnico em sobrevivência - pois o carioca é, antes de tudo, um forte. Se às vezes saio do Rio por algum tempo para descansar de seus perigos e desconfortos (certa vez inventei até ser correspondente de guerra, para ter um pouco de paz) a verdade é que sempre volto. Acostumei-me, assim, a viver perigosamente. Não sou covarde como esses equilibristas estrangeiros que passeiam sobre fios entre os edifícios. Vejo-os lá em cima, longe, dos ônibus e lotações, atravessando a rua pelos ares e murmuro: eu quero ver é no chão. (BRAGA, 2002).

A crônica, escrita em junho de 1951, quando o Rio de Janeiro era ainda o Distrito Federal, é repleta de ironia. Criticando o problema da violência urbana, que já parecia assolar a capital federal a ponto de Braga comparar sua experiência em passear pelas ruas de Ipanema e Copacabana a sua trajetória como correspondente de guerra (ele que acompanhou a Força Expedicionária Brasileira em sua campanha na Itália, durante a Segunda Guerra Mundial), a carta endereçada ao então recém-eleito prefeito João Carlos Vidal alude a figuras políticas pitorescas da época, como o deputado Tenório Cavalcanti 
(popularmente conhecido como "Homem da Capa Preta” - título de um filme inspirado em sua vida), que segundo reza a lenda costumava andar armado com uma metralhadora que apelidara "lurdinha" (nome que os expedicionários da FEB utilizavam para denominá-la, devido ao som estridente que fazia, supostamente semelhante ao grito de uma mulher).

O retrato caricato se estende à cidade, que é descrita, ferinamente, pelo "ar dos escapamentos abertos” e os banhos na praia do Leblon, "um dos mais lindos esgotos do mundo”. O efeito satírico é reforçado pelo tratamento "senhor", que é reiteradamente utilizado por Braga, que parece piscar para o seu leitor e alertá-lo: "lembre-se, você está lendo uma coluna de jornal mas isso aqui é na verdade uma carta endereçada ao prefeito”. Quando a interlocução parece se dissipar, eis que o cronista recupera a figura do destinatário de sua mensagem, dirigindo-se a ele sem perder a oportunidade para o deboche, sacando uma anacrônica segunda pessoa do plural: "E compreendo que, embora vós administreis à maneira suíça, nós continuaremos a viver à maneira carioca”.

É curioso como Braga (que sintomaticamente é o autor de uma das mis famosas versões modernas da carta de Pero Vaz de Caminha que conhecemos) parece parodiar a linguagem então usual entre escrivães como o nobre português, colocando-a a serviço, agora, não do elogio à exuberância idílica de um paraíso encontrado no meio do oceano, mas no que ele se transformou alguns séculos depois: um território de metrópoles que, como o Rio de Janeiro, sofre com o escárnio da natureza que ameaça inundar as ruas e carregar os cidadãos que passeiam alheios ao desastre, viajando confortáveis dentro de táxis urbanos.

Ao fim, ridicularizando a promessa do prefeito de "acabar em 30 dias com as inundações no Rio de Janeiro”, Rubem Braga toma o parlamentar como uma deidade, um demiurgo que, com o povo como testemunha, fez parar de chover e ainda por cima é capaz de instalar uma lua cheia sem precedentes sobre o mar de Copacabana. Assim ele arremata a crônica:

Mas não é para dizer isso que vos escrevo. É para agradecer a providência que vossa administração tomou nestas últimas quatro noites, instalando uma esplêndida lua cheia em Copacabana. Não sei se a fizestes adquirir na Suíça para nosso uso permanente, ou se é nacional. Talvez só possamos obter uma lua cheia definitiva reformando a Constituição e libertando Vargas.

Mas a verdade é que o luar sobre as ondas me consolou o peito. E eu andava muito precisado. Obrigado, Senhor. (BRAGA, 2002).

Novamente, o que é ironia em Braga tem um paralelo mais denotativo em Caminha, que para o fim escuso de trazer seu genro Jorge Osório da Ilha de São Tomé, numa das primeiras tentativas de negociatas de que se tem história nesse país que parece nascer sob a égide da fraqueza de caráter, adula Vossa Alteza como um mensageiro da providência, o responsável por 
lançar a semente que vai salvar a nossa gente. Caminha encerra beijando as mãos de Dom Manuel, mas não espera que suas mãos estejam vazias.

\section{Do prefeito ao vizinho do nono andar}

Em Recado ao Senhor 903, a interlocução literária já não se dá mais mediada por qualquer relação de poder. Aqui, Rubem Braga é o “vizinho”, o "homem do 1003” que, instado pelo zelador - o qual, numa consternada visita, transmite as reclamações do "senhor 903” a respeito do barulho -, diz-se "desolado" e adota um tom conciliatório a fim de minimizar a contenda com o condômino que tem como teto o seu piso.

Quem fala aqui é o homem do 1003. Recebi outro dia, consternado, a visita do zelador, que me mostrou a carta em que o senhor reclama contra o barulho em meu apartamento. Recebi depois a sua própria visita pessoal - devia ser meia-noite - e a sua veemente reclamação verbal. Devo dizer que estou desolado com tudo isso, e lhe dou inteira razão. O regulamento do prédio é explicito e, se não fosse, o senhor ainda teria ao seu lado a lei e a polícia. Quem trabalha o dia inteiro tem direito ao repouso noturno e é impossível repousar no 903 quando há vozes, passos e músicas no 1003. Ou melhor: é impossível ao 903 dormir quando o 1003 se agita; pois como não sei o seu nome nem o senhor sabe o meu, ficamos reduzidos a ser dois números, dois números empilhados entre dezenas de outros. (BRAGA, 1991).

É interessante observar como os personagens, nesta crônica - mais até que na anterior -, estão despojadas de sua "razão social”: são pessoas comuns, sem qualquer papel sugestivo no mundo além do de habitarem um condomínio. Personagens tão anódinos que podem até ser anônimos ou reduzidos somente a números: porque é assim, com números, que depois da introdução do texto o autor passa a denominar-se e denominar o receptor do seu “recado" - 903 e 1003, "pois como não sei o seu nome nem o senhor sabe o meu”, escreve Braga, “ficamos reduzidos a dois números, dois números empilhados entre dezenas de outros”.

Como aponta Larissa Leal Neves, "homem do 1003" e "Senhor 903” são sujeitos típicos do capitalismo, vivendo a utopia melancólica da modernidade. Escrita em 1953, num momento brevemente posterior à Carta ao Prefeito, esta crônica descortina uma transformação na realidade social do país:

É quando se insere, definitivamente, na lógica da industrialização e, com isso, participa de maneira diferente, mais direta, do sistema capitalista. Além disso, sente-se, a partir desse elemento, a tensão moderna de maneira mais aguda: convivem, em um mesmo espaço, tempos diferentes, visões “tradicionais” e visões “modernas”, o velho e o novo. Assim, mais importante que a industrialização brasileira em si é a consciência que se inicia em torno desse processo: a percepção mais efetiva da "mudança dos tempos” e dos seus paradigmas. (NEVES, 2015, p. 02). 
A ironia aparece aqui como um elemento que reflete o choque entre essas visões: a tradicional, representada pela do "Senhor 903", que reclama do barulho do vizinho, e a moderna, representada pela do "homem do 1003”, que agita-se em horário de repouso, fazendo ouvir os passos, as vozes e as músicas do seu apartamento. Para Neves, Braga leva ao limite a ideia da “reificação”, tornando os números (valores quantitativos) índices da subjetividade (valor qualitativo) desses dois personagens. Citando o que Löwy (2008, p. 36-37) entende por reificação:

[a] característica central da civilização industrial (burguesa) que o romantismo critica [...] é a quantificação da vida, isto é, a total 8 Embora o trabalho de Raymond Williams seja, em essência, um estudo da ideia de campo e cidade na literatura inglesa, muitas de suas observações são ampliadas para as manifestações ocidentais das mesmas, especialmente porque ele trabalha com a história das ideias, e são essas que aqui aparecem. dominação do valor de troca (quantitativo), do cálculo frio do preço e do lucro, e das leis do mercado acima do conjunto do tecido social. Todas as outras características negativas da sociedade moderna são intuitivamente sentidas pela maior parte dos anticapitalistas românticos como fluindo dessa crucial e decisiva nascente de corrupção: por exemplo, a religião ao deus dinheiro [...], o declínio de todos os valores qualitativos - da ordem social, religiosa, ética, cultural ou estética -, a dissolução de todos os vínculos humanos qualitativos, a morte da imaginação e do romance, a uniformização monótona da vida, a relação puramente "utilitária” - isto é, quantitativamente calculável - dos seres humanos entre si e com a natureza. (NEVES, 2015, p. 06-07)

Cumpre destacar o que essa reificação númerica denota: agora, o cronista não é mais um oficial enviado do reino, nem sequer um cidadão exercitando o seu direito (ainda que à desobediência civil), mas uma estatística. Um desconhecido, um popular, que não está incumbido de uma grande missão, não se propõe a ser ouvido por uma figura pública, mas que se comunica com um igual por meio de um "recado", um bilhete curto e informal, para ser passado por baixo da porta.

No nível da linguagem, é a crônica enfim se aproximando da coloquialidade que Davi Arrigucci Jr. menciona em seu Fragmento sobre a Crônica:

Esse gênero de literatura ligado ao jornal está entre nós há mais e um século e se aclimatou com tal naturalidade, que parece nosso. Despretensiosa, próxima da conversa e da vida de todo dia, a crônica tem sido, salvo alguma infidelidade mútua, companheira quase que diária do leitor brasileiro. No entanto, apesar de aparentemente fácil quanto aos temas e à linguagem coloquial, é difícil de definir como tantas coisas simples. (ARRIGUCCI JR., 1987, p. 51).

$\mathrm{Ou}$, ainda tratando deste aspecto coloquial, complexo como tantas coisas simples, àquilo que, um século antes, Machado de Assis cogitava 
quando tentava investigar a origem da crônica em seu delicioso texto $O$ Nascimento da Crônica:

Não posso dizer positivamente em que ano nasceu a crônica; mas há toda a probabilidade de crer que foi coetânea das primeiras duas vizinhas. Essas vizinhas, entre o jantar e a merenda, sentaram-se à porta, para debicar os sucessos do dia. Provavelmente começaram a lastimar-se do calor. Uma dizia que não pudera comer ao jantar, outra que tinha a camisa mais ensopando que as ervas que comera. Passar das ervas às plantações do morador fronteiro, e logo às tropelias amatórias do dito morador, e ao resto, era a coisa mais fácil, natural e possível do mundo. Eis a origem da crônica. (ASSIS, 2007, p. 17).

Se, diferente das vizinhas de Machado, os vizinhos de Braga não vivem mais lado a lado, mas cada um em um andar; e se, de forma distinta, não conversam mais para reclamar do calor, mas para se queixar do barulho que o outro faz fora do horário estipulado pelo regulamento do prédio, continuam os vizinhos “debicando” através da crônica, lamentando-se mesmo (como faz Rubem Braga) desta "outra vida”, em “outro “mundo" (no passado, talvez, como o que Machado viveu), em que se podia bater à porta de outros moradores e se confraternizar como velhos amigos.

\section{Conclusão}

A partir da análise comparativa da Carta ao Rei D. Manuel, de Pero Vaz de Caminha, e das crônicas Carta ao Prefeito e Recado ao Senhor 903, de Rubem Braga, notamos um percurso evolutivo da crônica como gênero, na medida em que seu aspecto circunstancial - antes submetido ao contexto de uma função designada (a do cronista de viagem) - foi se deslocando com o tempo para uma dimensão mais subjetiva do cotidiano e para uma apreensão mais particular desta realidade pelo cronista.

Após seu aporte nos jornais, por meio das narrativas folhetinescas, a crônica foi se tornando mais suscetível às contingências do transitório e chegando mais perto do que Antonio Candido (2003, p. 88) chamava do “rés-do-chão": a perspectiva daqueles que escrevem não do alto, mas da base da montanha.

Assim, o gênero passou a abarcar também recursos como o humor, valendo-se da ironia como um importante instrumento de percepção de mundo e crítica ao estabilishment.

Nas duas crônicas escritas por Rubem Braga, constatamos ainda a sua herança epistolar, um patrimônio que a crônica nunca perdeu. Até quando a sua estrutura não se assemelha a uma missiva, como contemporaneamente tem se visto na maioria dos textos publicados nas colunas que ainda restam, nos jornais que ainda lhe acolhem, a crônica conserva essa nuance, num tipo de discurso que vez ou outra acaba resvalando no franco diálogo com o leitor. 
Neste gênero, mais do que em qualquer outro, é a leitura, como Descartes e Ruskin acreditavam, uma “conversa entre espíritos”. Quiçá não entre os maiores, mas os que se pretendem menores, e em sua humildade encontram sua verdadeira grandeza.

\section{Referências}

ALMEIDA, Heloisa. Questão de gênero: o gênero textual crônica. Revista Na ponta do lápis. São Paulo: Cenpec, ano IV, v. 10, dez. 2008. Disponível em: <https://www.escrevendoofuturo.org.br/conteudo/biblioteca/nossaspublicacoes/revista/artigos/artigo/1235/questao-de-genero-o-generotextual-cronica>. Acesso em: 13 nov. 2017.

ARRIGUCCI JR., Davi. Fragmentos sobre a cronica. In: Enigma e comentário. São Paulo: Companhia das Letras, 1987.

BARBOSA, Amilcar Bettega. Da leitura à escrita: a construção de um texto, a formação de um escritor. 2012. Tese (Doutorado em Escrita Criativa) - Programa de Pós-Graduação em Letras, Faculdade de Letras, Pontifícia Universidade Católica do Rio Grande do Sul; Université Sorbonne Nouvelle - Paris 3, Porto Alegre, 2012.

BÍBLIA. Bíblia de Jerusalém. Nova ed. rev. e amp. São Paulo: Paulus, 2002.

. Tradução ecumênica da Bíblia. São Paulo: Loyola, 1994.

BRAGA, Rubem. Para Gostar de Ler. São Paulo: Ática, 2002. Disponível em: <http://portugues.camerapro.com.br/texto-para-interpretacao-89carta-ao-prefeito-nivel-fundamental/> . Acesso em: 03 dez. 2017.

. Para Gostar de Ler. São Paulo: Ática, 1991. Disponível em: <http://www.fieb.edu.br/reposicao/Maria_Theodora/Medio/3serie/maria_ theodora_medio_3serie_TR_aula03.pdf>. Acesso em: 04 dez. 2017.

CAMINHA, Pero Vaz. Carta ao rei D. Manuel. Adaptação: Rubem Braga. Rio de Janeiro: BestBolso, 2015.

CANDIDO, Antonio. A vida ao rés do chão. In: Para Gostar de Ler: crônicas. São Paulo: Ática, 2003. v. 5, p. 89-99

CRÔNICA DO JAPÃO. Biblioteca digital mundial. Washington: Library of Congress, 19. jun. 2017. v. 1 e 2. Disponível em: <https://www.wdl.org/ pt/item/11835/>. Acesso em: 13 nov. 2017.

BRESCIANI, Edda. Demotic chronicle. Encyclopaedia Iranica. New York: Columbia University, v. VII, fasc. 3, 1994. Disponível em: <http:// www.iranicaonline.org/articles/demotic-chronicle>. Acesso em: 13 nov. 2017. 
LÖWY, Michael. Romantismo e messianismo: ensaios sobre Lukács e Benjamin. Trad. Myrin Veras Baptista e Magdalena Pizante Baptista. São Paulo: Perspectiva, 2008.

MOISÉS, Massaud. A criação literária: prosa II. 16. ed. São Paulo: Cultrix [199-].

REIS, Douglas Ricardo Herminio Reis. A literatura no jornal: José de Alencar e os folhetins. 2011. Dissertação (Mestrado em Letras). Programa de Pós-Graduação em Letras, Instituto de Biociências, Letras e Ciências Exatas, Universidade Estadual Paulista. São José do Rio Preto, 2011.

RAMALHO, Christina. Sobre a invocação épica. Cadernos de Letras da UFF - Dossiê: Língua em uso, n. 47, p. 373-391, 2013.

SÁ, Jorge de. A Crônica. São Paulo: Ática, 2005.

SETO, Claudio. Pré-História do Japão 1: Kojiki e Nihon Shoki, os livros sagrados do Japão. Arquivo NippoBrasil. Edição 65. São Paulo: 10 a 16 ago. 2000. Disponível em: <http://www.nippo.com.br/historiadojapao/ n065.php>. Acesso em: 13 nov. 2017.

Enviado em maio/2018.

Aceito em dezembro/2018. 